\title{
Development and assessment of a cutaneous tissue stretch device as a novel scar therapy
} \author{
Mirko Gilardino', Satya Prakash ${ }^{6}$ \\ ${ }^{1}$ Division of Plastic and Reconstructive Surgery, McGill University Health Centre, Montreal, QC H3G 1B3, Canada. \\ ${ }^{2}$ Section of Plastic and Reconstructive Surgery, University of Manitoba, Winnipeg, MB R3T 2N2, Canada. \\ ${ }^{3} \mathrm{Mc}$ Gill Medical School, McGill University, Montreal, QC H3G 2M1, Canada. \\ ${ }^{4}$ Division of General Surgery, University of Sherbrooke, Sherbrooke, QC J1K 2R1, Canada. \\ ${ }^{5}$ Division of Plastic and Reconstructive Surgery, Indiana University, Indianapolis, IN 46202, USA. \\ ${ }^{6}$ Biomedical Engineering Department, Artificial Cells and Organs Research Centre, Montreal, QC H3A 2B4, Canada.
}

Jonathan Kanevsky ${ }^{1}$, Joshua Vorstenbosch², Julian Diaz-Abele², Tyler Safran ${ }^{3}$, Markus Prinz ${ }^{4}$, Youssef Tahiri ${ }^{5}$,

Correspondence to: Prof. Satya Prakash, Biomedical Engineering Department, Artificial Cells and Organs Research Centre, Duff Medical Building, 3775 University Street, Room 311, Montreal, QC H3A 2B4, Canada. E-mail: satya.prakash@mcgill.ca

How to cite this article: Kanevsky J, Vorstenbosch J, Diaz-Abele J, Safran T, Prinz M, Tahiri Y, Gilardino M, Prakash S. Development and assessment of a cutaneous tissue stretch device as a novel scar therapy. Plast Aesthet Res 2016;3:351-8.

Article history:

Received: 15-04-2016

Accepted: 27-10-2016

Published: 15-11-2016

Key words:

Mechanotransduction,

scar therapy,

hypertrophic scar,

skin stretch

\section{INTRODUCTION}

Scar formation can be a debilitating consequence of surgery, burns, trauma, or disease. Scarring can result

\section{ABSTRACT}

\begin{abstract}
Aim: Scar prevention and reduction is an area of therapeutic opportunity and unmet medical need. With no current effective scar therapy, patients are often disappointed in their appearance post surgery and re-present to surgeons, only to be turned away. The purpose of this study was to develop and test a device that produces intermittent parallel stretch on new scars and to analyze its potential to reduce scarring. Methods: Mice were randomized into 5 scar stretch treatment groups: 1 control, 1 sham, and 3 stretch models $(0.5 \times, 1 \times$, or $2 \times$ device strength $)$ and treated for 10 days. Scars were scored using the Vancouver Scar Scale. Scar tissue samples were compared by histology and transforming growth factor beta 1 (TGF- $\beta 1$ ) expression between control and treatment groups. Results: Scar scores of $0.5 \times$ and $1 \times$ groups were significantly lower than the control group $(P<0.05)$. Scar scores from the $1 \times$ treatment group were also significantly lower than the $0.5 \times$ group $(P<0.05)$. Sham, control scar and $2 \times$ groups showed more collagen deposition and a thicker dermal scar than the $0.5 \times$ and $1 \times$ groups. Unstretched scars had fewer fibroblasts with more collagen deposition than the $0.5 \times$ and $2 \times$ groups. TGF- $\beta 1$ levels were significantly lower in the $0.5 \times(342.1 \pm 9.2)$ and $1 \times(254.1 \pm 3.1)$ groups than in the control group $(P<0.05)$. TGF- $\beta 1$ levels in the $1 \times$ treatment group were also significantly lower than the $0.5 \times$ treatment group $(P<0.05)$. Conclusion: Intermittent cutaneous tissue stretch parallel to scars during the proliferative phase of wound healing decreases fibrosis on a macroscopic, microscopic and biochemical level.
\end{abstract}

in loss of function, restriction of movement, adverse psychological effects due to appearance and reduced quality of life..$^{[1-5]}$ Patients across wide demographic groups, gender, age, ethnicity, and geographic region 
have similar concerns about scarring and value even small improvements in scarring. ${ }^{[6-11]}$ Changes in texture, coloration and elevation of scar are of equal concern to patients with minor and severe scars. ${ }^{[5,12]}$ In addition to scars on the face, patients are often dissatisfied with scars from donor graft sites used for breast reconstruction, heart surgery, and elective procedures such as abdominoplasty. ${ }^{[13,14]}$

Scar prevention and reduction is an area of therapeutic opportunity and unmet medical need. There is no single therapy that is accepted as the standard of care for treatment of scars. ${ }^{[15-17]}$ Many patients seek surgery for scar revision but surgeons often turn away patients, as they believe that improved results cannot be obtained with current techniques and therapies. ${ }^{[12]}$ In the US alone, 45 million patients undergo procedures yearly that would benefit from scar reduction therapy. ${ }^{[18]}$

Current scar therapies lack a clear mechanism of action and have unpredictable efficacy. Non-surgical therapies include topical creams and preparations, wound dressings, laser treatments, and skin substitutes. Additional therapies such as massage and mechanical manipulation have also been often recommended to patients for treatment of scars with variable results. ${ }^{[19-21]}$

To better understand then mechanism behind scar formation, the role of mechanical force in scar formation has been explored extensively. ${ }^{[2-25]}$ Studies have shown that tension resisting wound closure can worsen scar formation. ${ }^{[25]}$ However, recent data suggests that the timing, duration, and direction of force on a scar plays an important factor in scar formation, and properly aligned and timed mechanical forces could potentially decrease scar formation. ${ }^{[26-29]} \mathrm{A}$ previous study by Alenghat and Ingber ${ }^{[30]}$ showed that mechcanotransduction directly affects a variety of cellular processes involved in scar formation. Although direct manipulation of these cellular processes is still being investigated, there has been an assortment of models examining the effects of direct skin manipulation on scar formation. A randomized-control trial (RCT) showed that using tape after surgery helped prevent hypertrophic scar formation in 70 patients..$^{[31]}$ Another study showed using a mouse model that when an incision is under mechanical stress, inflammatory cells become activated and apoptosis of the healing cells increases. ${ }^{[32]}$ Additionally, a review on all currently hypothesized physical treatment modalities for scar prevention and found that the success of compression therapy, silicone therapy, adhesive tape, and occlusive dressing therapy, relies on mechanotransduction mechanisms. ${ }^{[2]}$ Furthermore, recent studies evaluating tension on wounds in a pig model formed the foundation for the Embrace device, which functions to reduce scar
A

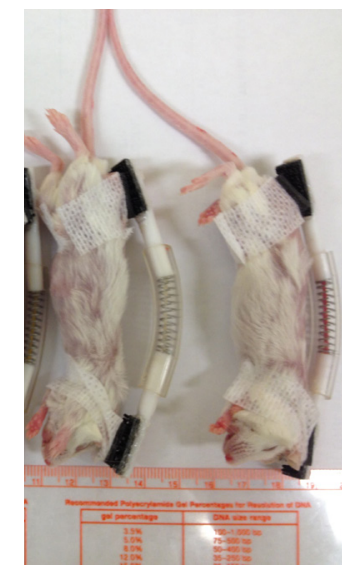

B

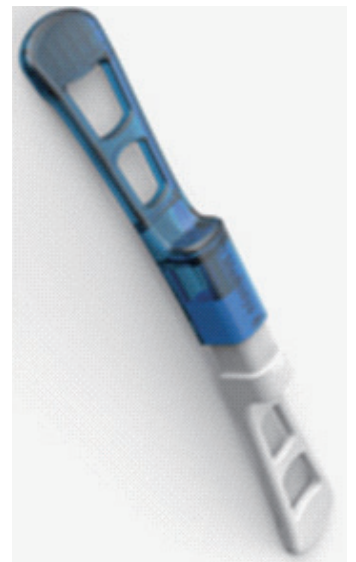

Figure 1: (A) Application of stretch device in vivo. Stretch treatments lasted $20 \mathrm{~min}$ once a day for 10 days. Mice were anesthetized under isoflurane for each stretch treatment; $(B)$ the actual design of the stretch device

formation by applying mechanical stress to oppose wound edges. ${ }^{[33,34]}$

Langevin et al. ${ }^{[26-28,35]}$ and Bouffard et al. ${ }^{[29]}$ have published a series of studies that demonstrate the decreased collagen and transforming growth factor beta 1 (TGF- $\beta 1$ ) expression, major contributors to scar formation, after longitudinal stretch parallel to a wound. Based on these data, the present study aims to develop a longitudinal stretch device that might enhance aesthetic outcome of scarring through modulation of the cellular processes involved in scar formation.

\section{METHODS}

\section{Device development and standardization}

AutoCAD was used to design a scar stretch device that could easily attach and detach from skin. The components of the device include a skin adhesive mechanism and an extension force mechanism, allowing for reliable attachment and detachment of the device [Figure 1]. The device prototypes were constructed using inert materials purchased from Small Parts Inc. (www.smallpartsinc.com): steel spring (Stainless Steel 316 Compression Spring), polyvinyl tubing (White Translucent Miniature PTFE Tubing), Teflon rods (PTFE Round Rod), and an adhesive. Three different spring strengths for the scar stretch devices were created and labeled as $0.5 \times, 1 \times$ and $2 \times$ to investigate a dose response $(1 \times=0.96$ Newton, as per manufacturer specifications). The devices were standardized to ensure similar extension force using a small force gauge (Jonard Industries, Tuckahoe, NY).

\section{Animal model}

The experimental protocol was approved by the McGill University Animal Care Committee and Institutional 


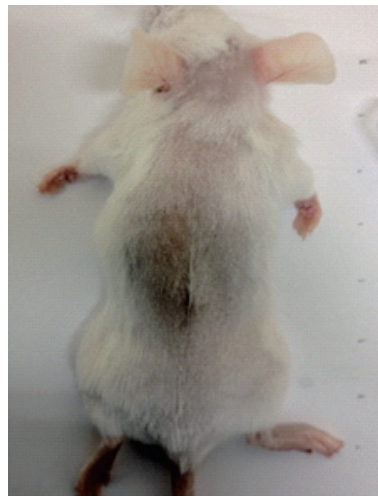

Control (1)

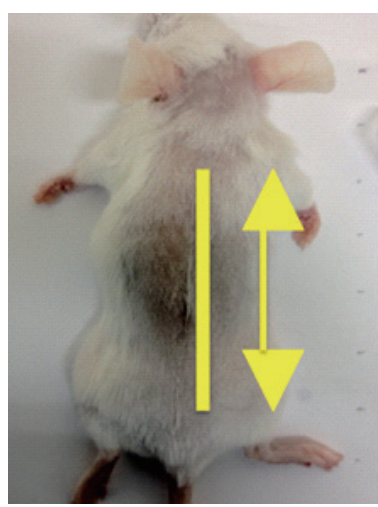

$0.5 \times(4)$

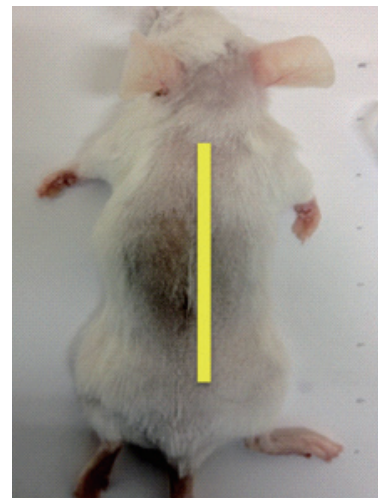

Control scar (2)

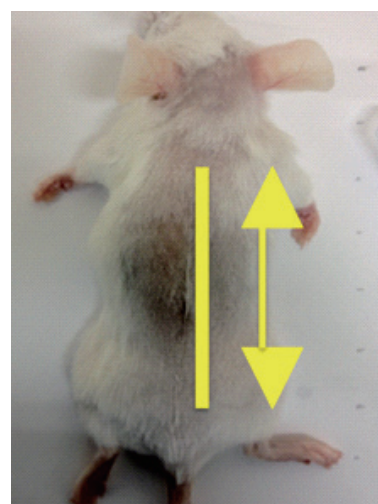

$1 \times(5)$

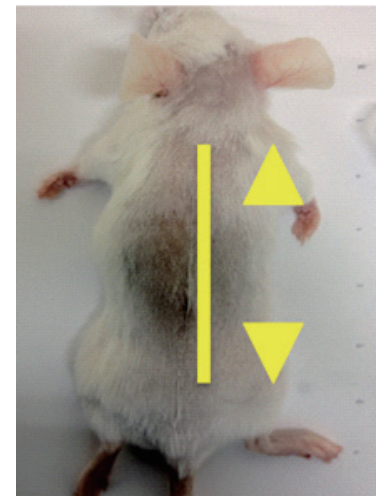

Sham (3)

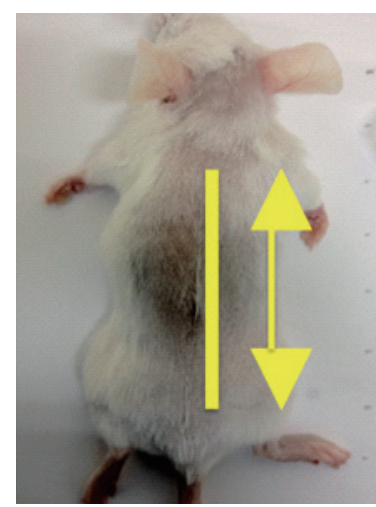

$2 \times(6)$

Figure 2: Representative mice from 5 stretch strength groups, with the incision and stretch guidelines. Control mouse and each stretch strength group are shown

Review Board. All mice were female, Balb/C weighing 19-21 g. Thirty mice were divided equally into 5 groups (control scar, sham, $0.5 \times, 1 \times, 2 \times$ ), with 1 mouse not making it into the control group [Figure 2]. After anesthesia was induced with isoflurane, mice were shaved and a 3-cm incision was made with a scalpel in the middle of the back at the level of the scapula as per the procedure described by Bouffard et al. ${ }^{[29]}$ Incisions were closed primarily with Steri-strips ${ }^{\mathrm{TM}}$ and were carefully observed to maintain close primary approximation. Steri-strips remained in place for five days until the device adhesive was applied. Mice were observed daily to confirm continuous primary closure of the wounds.

\section{In vivo tissue stretch method}

On day 5 post-incision in all mice, 2 U-lock mechanisms were adhered cranial and caudal to the incision, without coming into contact with the wound. The device was aligned in parallel over the scar by attaching the ends of the device to the U-lock mechanism for a 20-min stretch period. Following the 20-min stretch period, the device was removed while the U-lock mechanism remained adhered on the dorsum of the mice. All mice underwent stretching of the trunk for 20 min once per day for 10 days, and mice in groups 2, 3, 4, 5 underwent stretch treatment with device under isoflurane anesthesia. Five days after the last stretch treatment, at 20 days postincision, all mice were euthanized. The wounds were harvested and bisected with one piece fixed in formalin for histology and the other snap frozen in liquid nitrogen for biochemical analysis.

\section{Morphologic scar assessment}

Photos of scars 15 days after beginning tissue stretch (20 days post incision) were qualitatively analyzed by two blinded reviewers using the Vancouver Scar Scale.

\section{Histologic analysis}

Following formalin fixation, tissues were embedded in paraffin and sectioned at $7 \mu \mathrm{m}$. Samples were mounted and stained with Masson-Trichrome to demonstrate collagen and examined using light microscopy. Two independent blinded histology trained observers evaluated stained sections qualitatively.

\section{Cutaneous TGF- $\beta 1$ assay}

Skin samples were harvested as above. Samples were then homogenized and immediately assayed for TGF- $\beta 1$ protein using a human TGF- $\beta 1$ ELISA assay as per manufacturer protocol to adjust for standard 


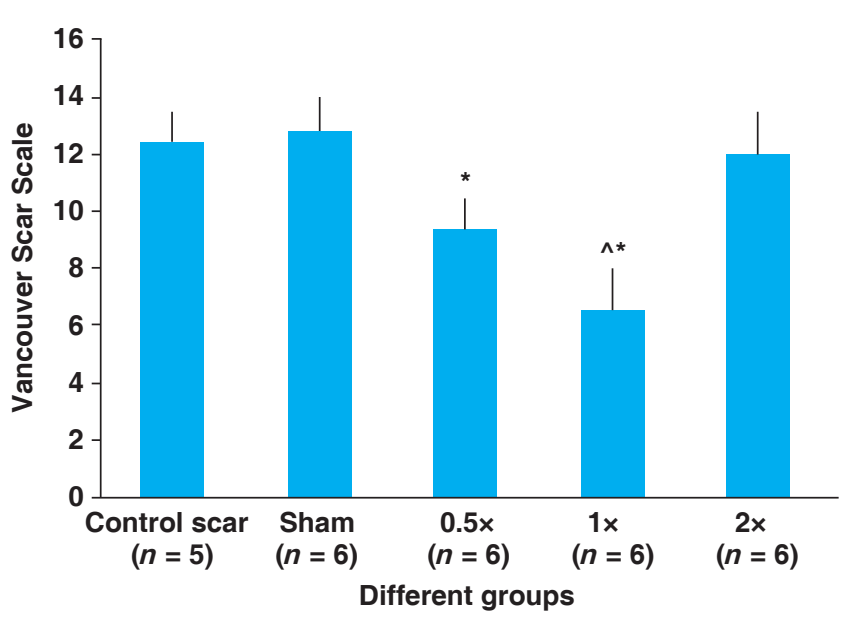

Figure 3: Morphological comparison of scars using Vancouver Scar Scale. *Significant difference from control scar group $(P<0.05)$; $\wedge$ Significant difference from $0.5 \times$ stretch group $(P<0.05)$. Standard deviation is represented by error bars

level of the sample (R\&D Systems, Minneapolis, MN), including sample acidification with $1 \mathrm{~N}$ hydrochloric acid for activation of latent TGF- $\beta 1$.

\section{Statistical analysis}

Analysis of variance (ANOVA) with Bonferroni correction for multiple variables was performed to test for differences of TGF- $\beta 1$ level and Vancouver Scar Scale scores between treatment groups. ANOVA was used to analyze the effects of stretch on TGF- $\beta 1$ concentrations after 5 days of the 10 consecutive days of stretch therapy. For these analyses, TGF- $\beta 1$ data were log transformed prior to analysis in order to satisfy the normality and homogeneity of variance assumptions associated with the ANOVA. Statistical analyses were performed using SAS statistical software (PROC MIXED). $P$ values $<0.05$ were considered statistically significant.

\section{RESULTS}

\section{Development of a scar stretch device}

A total of 29 devices were created and grouped into
4 different stretch strength categories. The force produced by each device, except the sham, was measured. The strength categories were: (1) a sham device, which consisted of the device without any spring mechanism that produced no extension force; (2) a $0.5 \times$ device which exerted a mean force of $265.6 \pm 1.5 \mathrm{~g}$; (3) a $1 \times$ device which exerted a mean force of $532.4 \pm 1.8 \mathrm{~g}$; and (4) a $2 \times$ device which exerted a mean force of $1,068.4 \pm 3.4 \mathrm{~g}$.

\section{Morphologic scar assessment}

Photos of scars 15 days after beginning tissue stretch (20 days post incision) were qualitatively analyzed using the Vancouver Scar Scale [Figures 3 and 4]. Control scars averaged $12.4 \pm 1.0$, sham scars $12.8 \pm 1.16$, $0.5 \times$ stretch treatment group $9.4 \pm 1.0,1 \times$ stretch treatment group $6.6 \pm 1.5,2 \times$ stretch treatment group $12 \pm 1.4$. Scar scores from the $0.5 \times$ and $1 \times$ stretch groups were significantly lower when compared to the control scar group $(P<0.05)$. Scar scores from the $1 \times$ treatment group were also significantly lower when compared to the $0.5 \times$ group $(P<0.05)$. On examination 20 days post incision ( 5 days after last stretch treatment) scars remained most visible in the sham, control, and $2 \times$ treatment groups [Figure 4].

\section{Qualitative histologic analysis}

Sham, control and $2 \times$ treatment groups showed greater collagen deposition and a thicker dermal scar than the $0.5 \times$ and $1 \times$ treatment groups [Figure 5]. The dermis in unstretched scars (sham and control treatment groups) had fewer fibroblasts and more collagen between cells than the $0.5 \times$ and $2 \times$ treatment groups, where fibroblasts were closely spaced [Figure 5].

\section{Cutaneous TGF- $\beta 1$ assay}

TGF- $\beta 1$ protein levels in cutaneous scars 20 days after incision were significantly higher in the control $(471.9 \pm 13.8 \mathrm{pg} / \mathrm{mL})$, sham $(383.3 \pm 49.2 \mathrm{pg} / \mathrm{mL})$ and $2 \times$ stretch $(401.3 \pm 41.1 \mathrm{pg} / \mathrm{mL})$ treatment groups. As shown in Figure 6, TGF- $\beta 1$ levels were

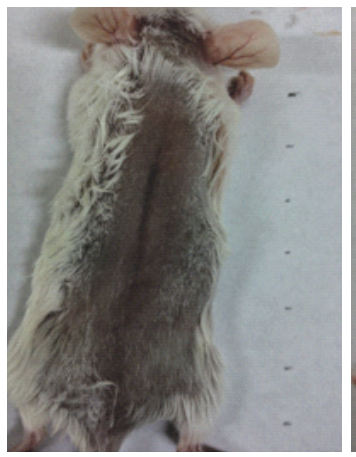

Control

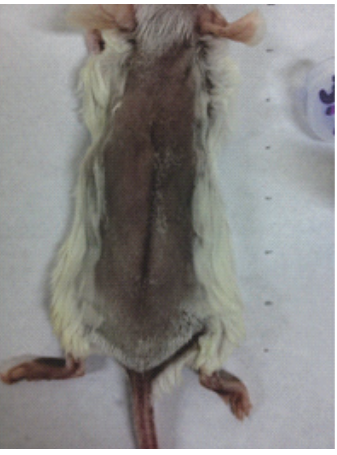

Sham

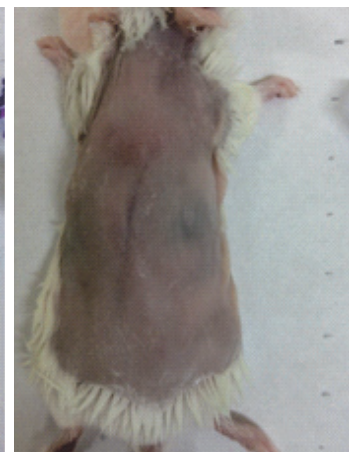

$0.5 \times$

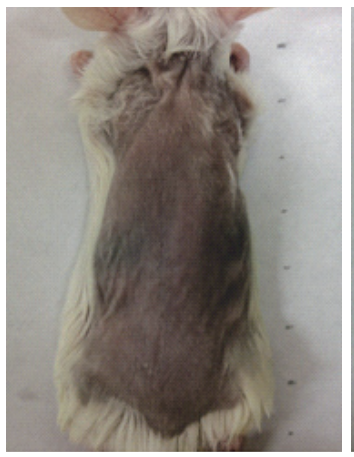

$1 \times$

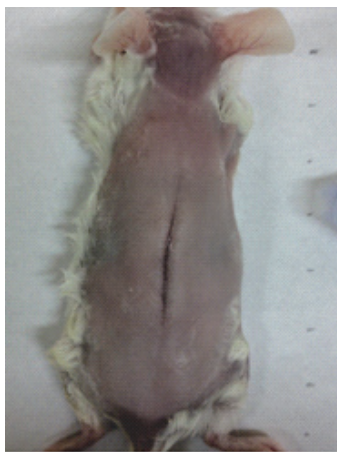

$2 x$

Figure 4: Representative mice from 5 groups 20 days after incision, 5 days after last stretch treatment. Control mouse without scar is not shown 


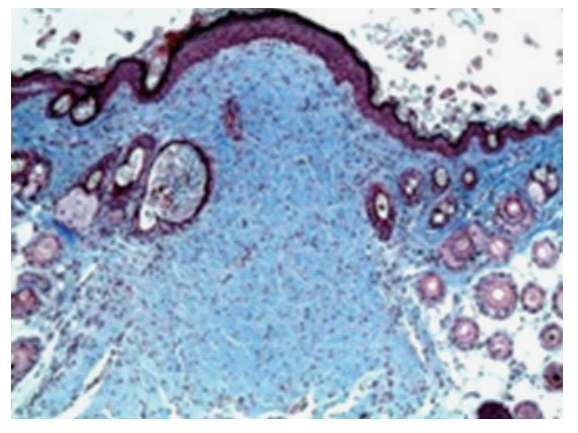

Control scar

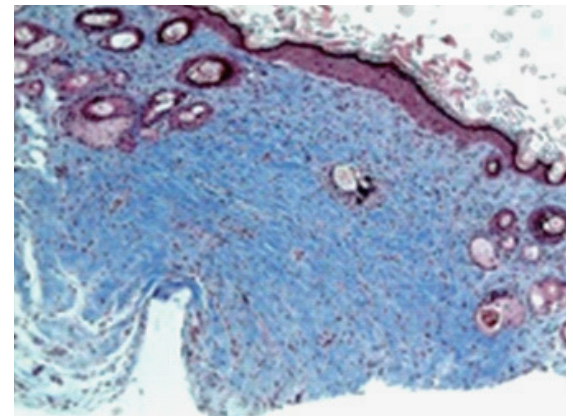

Sham

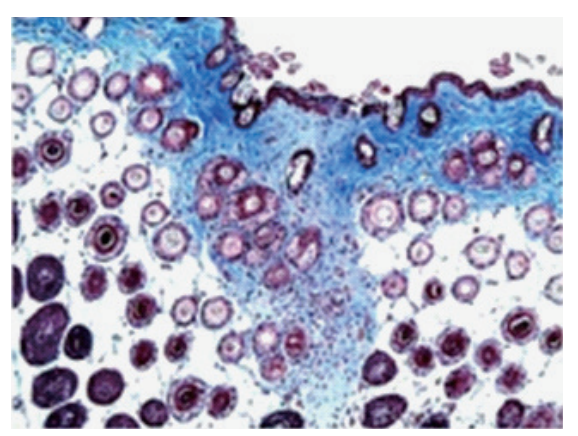

$0.5 x$

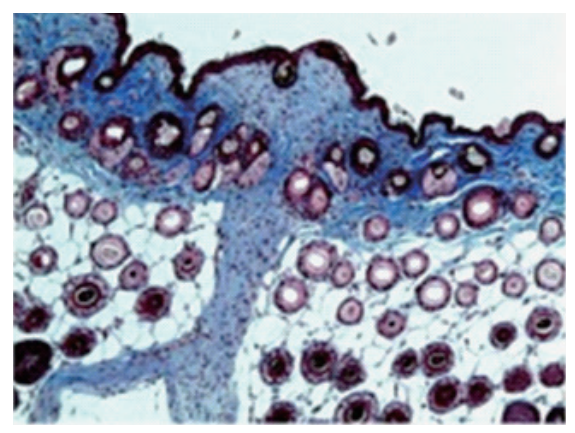

$1 \times$

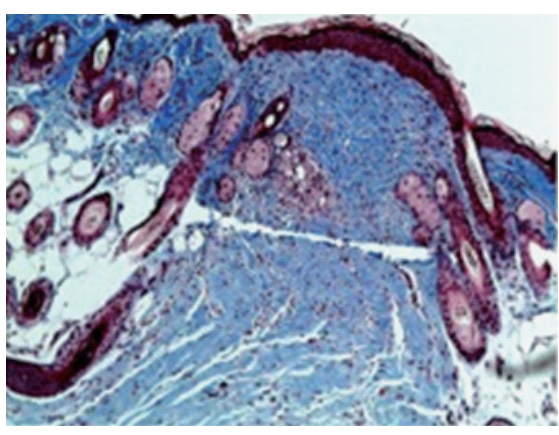

$2 \times$

Figure 5: Mouse in vivo stretch model. Effect of stretch on cutaneous scar formation. Masson Trichrome (stains collagen blue) of paraffin embedded histological sections cut perpendicular to the skin at 10x magnification

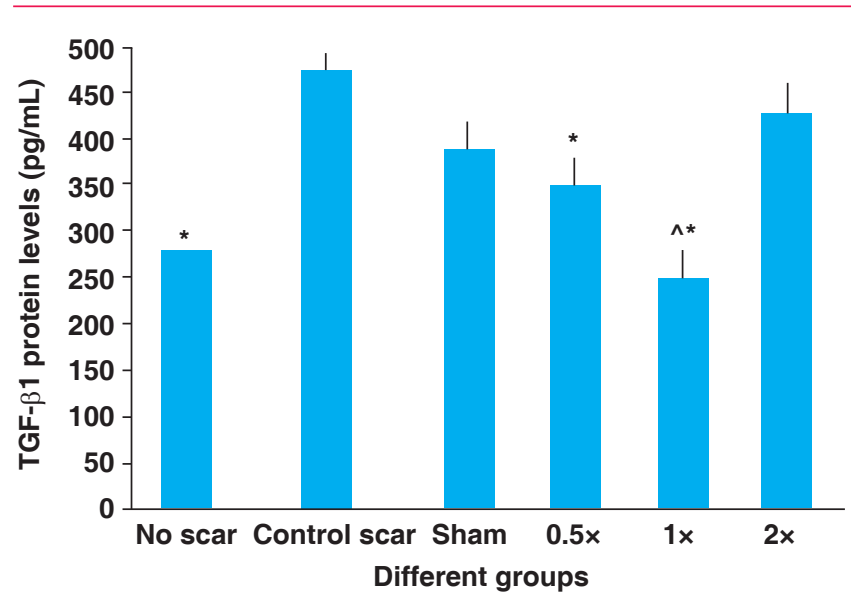

Figure 6: Levels of transforming growth factor beta 1 (TGF- $\beta 1$ ) protein in cutaneous scar at day 20 for non-stretched and stretched tissue samples. *Significant difference from control scar group $(P$ $<0.05)$; ^Significant difference from $0.5 \times$ stretch group $(P<0.05)$. Standard deviation is represented by error bars

significantly lower in the stretch treatment groups $0.5 \times$ $(342.1 \pm 9.2 \mathrm{pg} / \mathrm{mL})$ and $1 \times(254.1 \pm 3.1 \mathrm{pg} / \mathrm{mL})$ when compared to the control scar group $(P<0.05)$. Furthermore, TGF- $\beta 1$ levels in the $1 \times$ treatment group were significantly lower than the $0.5 \times$ treatment group $(P<0.05)$ [Figure 6].

\section{DISCUSSION}

Results of the present study demonstrate that linear stretch parallel to incisional wounds reduces scarring.
Using a newly developed cutaneous stretch device, animals treated with the device demonstrated less scarring from a morphologic, histologic, and molecular perspective. Benefits included improved scar appearance, decreased collagen deposition in the dermis and decreased TGF- $\beta 1$ production.

This study demonstrates that application of linear cutaneous stretch parallel to incisional wounds reduces scarring on both macroscopic and microscopic levels. Critics of other scar reducing device papers found that only examining the aesthetic outcome of the scar is not sufficient in determining the success of the device. ${ }^{[34,35]}$ The Vancouver scar scale is comprised of four variables, which are extremely recognizable to the patient: vascularity, height/thickness, pliability, and pigmentation. ${ }^{[36]}$ This scale was selected due its relative common use in scar research, user objectivity, ease of use, and assessment of variables important to patients. The correlation of the reduction in scarring grossly and histologically supports the utility of linear cutaneous stretch in treatment of scars.

Although the exact mechanism behind the improvement in scars with linear scar stretch is unknown, one explanation is that linear stretch may decrease scar formation by minimizing perpendicular tension across the wound and thus promoting approximation of wound edges. The stretch force and overall stretch 
time (total of 20 min per day) used in our study are both less when compared to other studies where skin was stretched continuously for long periods of time under higher tension. ${ }^{[22-24,37]}$ In these studies prolonged tissue stretch under high tension caused release of inflammatory mediators that promoted scar formation. ${ }^{[24,38]}$ Although such previous studies have demonstrated tissue stretch can induce scar formation, the discussion on timing, force and duration of stretch required to induce a scar remains unclear. $^{[22-24,38]}$ The results from the $2 \times$ stretch group in the present study provides some support for the detrimental effects of high-tension tissue stretch, where scars in this group were comparable to controls (non-stretched scars). In addition to worse appearing scars, the $2 \times$ group also had more collagen deposition in the dermis, and higher levels of TGF- $\beta 1$. Compared to the favorable scar results in the $0.5 \times$ and $1 \times$ groups, the latter data suggests that there is a threshold of tension, above which tissue stretch promotes scar formation and below which tissue stretch may decrease scar formation.

Substantial evidence describes the role of mechanotransduction in scar formation. Our study builds on preliminary findings that controlling tension in a proliferating scar modulates production of extracellular matrix proteins. Langevin et al. ${ }^{[26-28,35]}$ described several cellular and extracellular matrix changes that take place once skin is stretched that promote decreased scar formation. Tissue stretch causes fibroblast cell spreading, cytoskeletal and nuclear remodeling, decreased type 1 collagen production and decreased production of TGF- $\beta 1$. A recent paper by Suarez et al. ${ }^{[37]}$ describes the role of tension in keloid pathology, specifically tension dependent proteins: Hsp27, $\alpha 2 \beta 1$-Integrin, and PAI-2. Furthermore, the clinical correlation of reduced fibrosis associated with intermittent parallel longitudinal tension and significant improvements in scar appearance using parallel scar massage offers further support for the clinical utility of the device presented herein. This suggests that tissue stretch induces mechanical signals that may regulate gene expression and overall function of fibroblasts.

It is important to note that this study is not without limitations. A murine model was used as a preliminary means to evaluate the efficacy of this novel device in modulating scar formation during the proliferative phase of wound healing. The cost and previous use of a murine model to study wound healing made mice a logical first choice of animal model for this investigation. Mouse skin is significantly different from human skin in elasticity and healing potential, limiting the direct translation of these findings to humans. This study evaluated end-points correlating to the early remodeling phase of wound healing, offering assessment of fibrosis but not long-term scar remodeling. Despite these differences, there still remain substantial similarities between the underlying wound healing physiology, providing promise for the utility of this device. However, future experiments are still planned to measure the effects of the device long term on scarring. These studies, also proposed in mice, will also allow for more extensive biochemical assessment of the device by measuring parameters associated with mechanotransduction, including focal adhesion kinase levels to better describe the underlying mechanism of the observed reduction in fibrosis. Additionally, further quantitative analysis of the number of fibroblasts in numerous sections, thickness of the scars and the epidermal thickness would have added to the analysis of scar reduction.

To further elaborate the elegant mechanisms at work in the modulation of scar formation the authors plan to evaluate the device in a skin scarring animal model more indicative of human scar biology, such as the red Duroc pig. ${ }^{[33]}$ While this study provides substantial promise for the device presented here, subsequent studies will establish more precisely the optimal vector, force, and duration of tissue stretch needed to effectively and consistently reduce scar formation. Optimizing such parameters may permit the development of a novel scar treatment device that could be used to treat a wide variety of scars.

Scar formation has detrimental effects on social, psychological, and physical function. ${ }^{[1-5]}$ Current scar therapies are poorly understood and insufficient to insure optimal scar formation. In one promising study, Lim et al. ${ }^{[39]}$ showed in a randomized clinical trial that their Embrace device, which differs significantly from the device used in this study, managed to achieve statistically significant results. The Embrace device reduces perpendicular tension by direct opposition rather than by application of parallel stretch described in this study. The device presented herein, applied only intermittently rather than continuously as is the Embrace device, appears to function similarly in that it ultimately opposes the wound edges. The present device is only in its infancy, and further investigations of the optimal time interval of use, vector of stretch, and magnitude of stretch provide hope for an effective treatment strategy for the reduction of scar formation.

In conclusion, in this study we designed and manufactured a device that may provide parallel tissue stretch to a wound in order to improve scar formation. Our results show that the $1 \times$ strength device is overall superior 
to other strengths and that tissue stretch is beneficial to scar formation in the molecular, histological and macroscopic levels. This device is a promising treatment to improve scar formation. It is safe and easy to use in clinical practice.

\section{Financial support and sponsorship}

Funding for the materials used in the animal study was provided by Menodys Inc.

\section{Conflicts of interest}

Jonathan Kanevsky, Mirko Gilardino, Satya Prakash are the inventors listed on the patent publication for the device and method used in this study (Patent: WO 2013071439 A1). Funding for the materials used in the animal study was provided by Menodys Inc., who is licensing the patent for the device used in this study from McGill University. Joshua Vorstenbosch, Julian Diaz-Abele, Markus Prinz, Youssef Tahiri and Tyler Safran have no actual or potential conflicts of interest.

\section{Patient consent}

There is no patient involved.

\section{Ethics approval}

The experimental study was approved by the McGill University Animal Care Committee and Institutional Review Board.

\section{REFERENCES}

1. Lawrence JW, Fauerbach JA, Heinberg L, Doctor M. Visible vs. hidden scars and their relation to body esteem. J Burn Care Rehabil 2004;25:25-32.

2. Bayat A, McGrouther DA. Clinical management of skin scarring. Skinmed 2005;4:165-73.

3. Newell R. Psychological difficulties amongst plastic surgery expatients following surgery to the face: a survey. Br J Plast Surg 2000;53:386-92.

4. Valente SM. Visual disfigurement and depression. Plast Surg Nurs 2009;29:10-6.

5. Rumsey N, Clarke A, White P. Exploring the psychosocial concerns of outpatients with disfiguring conditions. $J$ Wound Care 2003;12:247-52.

6. McGrouther DA. Facial disfigurement. BMJ 1997;314:991.

7. Bragg TW, Jose RM, Srivastava S. Patient satisfaction following abdominoplasty: an NHS experience. J Plast Reconstr Aesthet Surg 2007;60:75-8.

8. Abu-Nab Z, Grunfeld EA. Satisfaction with outcome and attitudes towards scarring among women undergoing breast reconstructive surgery. Patient Educ Couns 2007;66:243-9.

9. Tebble NJ, Thomas DW, Price P. Anxiety and self-consciousness in patients with minor facial lacerations. $J$ Adv Nurs 2004;47:417-26.

10. Levine E, Degutis L, Pruzinsky T, Shin J, Persing JA. Quality of life and facial trauma: psychological and body image effects. Ann Plast Surg 2005;54:502-10.

11. Robert R, Meyer W, Bishop S, Rosenberg L, Murphy L, Blakeney P. Disfiguring burn scars and adolescent self-esteem. Burns
1999;25:581-5.

12. Occleston NL, O'Kane S, Goldspink N, Ferguson MW. New therapeutics for the prevention and reduction of scarring. Drug Discov Today 2008;13:973-81.

13. Stewart KJ, Stewart DA, Coghlan B, Harrison DH, Jones BM, Waterhouse N. Complications of 278 consecutive abdominoplasties. J Plast Reconstr Aesthet Surg 2006;59:1152-5.

14. Crossland DS, Jackson SP, Lyall R, Hamilton JR, Hasan A, Burn J, O'Sullivan JJ. Patient attitudes to sternotomy and thoracotomy scars. Thorac Cardiovasc Surg 2005;53:93-5.

15. Franz MG, Steed DL, Robson MC. Optimizing healing of the acute wound by minimizing complications. Curr Probl Surg 2007;44:691763.

16. Batra RS. Surgical techniques for scar revision. Skin Therapy Lett 2005;10:4-7.

17. Meier K, Nanney LB. Emerging new drugs for scar reduction. Expert Opin Emerg Drugs 2006;11:39-47.

18. Sen CK, Gordillo GM, Roy S, Kirsner R, Lambert L, Hunt TK, Gottrup F, Gurtner GC, Longaker MT. Human skin wounds: a major and snowballing threat to public health and the economy. Wound Repair Regen 2009;17:763-71.

19. Field T, Peck M, Scd, Hernandez-Reif M, Krugman S, Burman I, Ozment-Schenck L. Postburn itching, pain, and psychological symptoms are reduced with massage therapy. J Burn Care Rehabil 2000;21:189-93.

20. Field T, Peck M, Krugman S, Tuchel T, Schanberg S, Kuhn C, Burman I. Burn injuries benefit from massage therapy. J Burn Care Rehabil 1998;19:241-4.

21. Foo CW, Tristani-Firouzi P. Topical modalities for treatment and prevention of postsurgical hypertrophic scars. Facial Plast Surg Clin North Am 2011;19:551-7.

22. Huang C, Akaishi S, Ogawa R. Mechanosignaling pathways in cutaneous scarring. Arch Dermatol Res 2012;304:589-97.

23. Ogawa R, Okai K, Tokumura F, Mori K, Ohmori Y, Huang C, Hyakusoku H, Akaishi S. The relationship between skin stretching/ contraction and pathologic scarring: the important role of mechanical forces in keloid generation. Wound Repair Regen 2012;20:149-57.

24. Yagmur C, Akaishi S, Ogawa R, Guneren E. Mechanical receptorrelated mechanisms in scar management: a review and hypothesis. Plast Reconstr Surg 2010;126:426-34.

25. Wong VW, Rustad KC, Akaishi S, Sorkin M, Glotzbach JP, Januszyk M, Nelson ER, Levi K, Paterno J, Vial IN, Kuang AA, Longaker MT, Gurtner GC. Focal adhesion kinase links mechanical force to skin fibrosis via inflammatory signaling. Nat Med 2012;18:148-52.

26. Langevin HM, Bouffard NA, Badger GJ, Iatridis JC, Howe AK. Dynamic fibroblast cytoskeletal response to subcutaneous tissue stretch ex vivo and in vivo. Am J Physiol Cell Physiol 2005;288:C747-56.

27. Langevin HM, Storch KN, Cipolla MJ, White SL, Buttolph TR, Taatjes DJ. Fibroblast spreading induced by connective tissue stretch involves intracellular redistribution of alpha- and beta-actin. Histochem Cell Biol 2006;125:487-95.

28. Langevin HM, Bouffard NA, Badger GJ, Churchill DL, Howe AK. Subcutaneous tissue fibroblast cytoskeletal remodeling induced by acupuncture: evidence for a mechanotransduction-based mechanism. J Cell Physiol 2006;207:767-74.

29. Bouffard NA, Cutroneo KR, Badger GJ, White SL, Buttolph TR, Ehrlich HP, Stevens-Tuttle D, Langevin HM. Tissue stretch decreases soluble TGF-beta1 and type-1 procollagen in mouse subcutaneous connective tissue: evidence from ex vivo and in vivo models. $J$ Cell Physiol 2008;214:389-95.

30. Alenghat FJ, Ingber DE. Mechanotransduction: all signals point to cytoskeleton, matrix, and integrins. Sci STKE 2002;2002:pe6. 
31. Von Offenberg Sweeney N, Cummins PM, Cotter EJ, Fitzpatrick PA, Birney YA, Redmond EM, Cahill PA. Cyclic strain- mediated regulation of vascular endothelial cell migration and tube formation. Biochem Biophys Res Commun 2005;329:573-82.

32. Aarabi S, Bhatt KA, Shi Y, Paterno J, Chang EI, Loh SA, Holmes JW, Longaker MT, Yee H, Gurtner GC. Mechanical load initiates hypertrophic scar formation through decreased cellular apoptosis. FASEB J 2007;21:3250-61.

33. Gurtner GC, Dauskardt RH, Wong VW, Bhatt KA, Wu K, Vial IN, Padois K, Korman JM, Longaker MT. Improving cutaneous scar formation by controlling the mechanical environment: large animal and phase I studies. Ann Surg 2011;254:217-25.

34. Gurtner GC, Longaker MT. Reply: tension shielding with the embrace device: does it really improve scars? Plast Reconstr Surg 2014;134:e664-6.

35. Langevin HM, Storch KN, Snapp RR, Bouffard NA, Badger GJ,
Howe AK, Taatjes DJ. Tissue stretch induces nuclear remodeling in connective tissue fibroblasts. Histochem Cell Biol 2010;133:405-15.

36. Baryza MJ, Baryza GA. The Vancouver Scar Scale: an administration tool and its interrater reliability. J Burn Care Rehabil 1995;16:535-8.

37. Suarez E, Syed F, Alonso-Rasgado T, Mandal P, Bayat A. Upregulation of tension-related proteins in keloids: knockdown of Hsp27, alpha2beta1- integrin, and PAI-2 shows convincing reduction of extracellular matrix production. Plast Reconstr Surg 2013;131:e158-73.

38. Chin MS, Lancerotto L, Helm DL, Dastouri P, Prsa MJ, Ottensmeyer M, Akaishi S, Orgill DP, Ogawa R. Analysis of neuropeptides in stretched skin. Plast Reconstr Surg 2009;124:102-13.

39. Lim AF, Weintraub J, Kaplan EN, Januszyk M, Cowley C, McLaughlin P, Beasley B, Gurtner GC, Longaker MT. The embrace device significantly decreases scarring following scar revision surgery in a randomized controlled trial. Plast Reconstr Surg 2014;133:398-405. 